\title{
Reverse Logistics from Recycling of Used Paper Boxes from Online Shopping in China: A Literature Review
}

\author{
Mustakim Melan', Tang Ying², Gao Chaomin ${ }^{3}$, Pichit Prapinit ${ }^{4}$, Mohamad Ghozali Hassan ${ }^{5}$ \\ ${ }^{1,5}$ Disaster Management Institute (DMI), School of Technology Management and Logistics, \\ College of Business, Universiti Utara Malaysia, 06010, Sintok, Kedah \\ ${ }^{2,3}$ School of Business Administration, University Baise, 53300 China \\ ${ }^{4}$ Loei Rajabhat University(LRU), Loei - Chiang Kan, loei, 42000, Thailand \\ mustakim@uum.edu.my ${ }^{1}$, ylyatt@live.com ${ }^{2}$, 26882493@qq.com ${ }^{3}$, pichitprapinit@gmail.com ${ }^{4}$, \\ ghozali@uum.edu.my ${ }^{5}$
}

Article History: Received: 10 November 2020; Revised: 12 January 2021; Accepted: 27January 2021; Published online: 05April 2021

\begin{abstract}
The study investigates on activities of returning the usage paper boxes through online shopping among universities' students in China. It also can investigate the similarity studies in online shopping at other countries and adopting the concept of reverse logistics.Online shopping is the most popular transaction at present especially among students and working adults for conveniences in lifestyles. Online shopping is able to reduce purchasing times, personal costs, having multiple choices with cheaper products. With regards of the package in on-line shopping, most of the sellers are using the designed paper boxes for packaging and sending them to their customers. Upon receiving, the buyers normally destroyed the paper boxes, throwing away into dust bin and some were kept for nothing. These will impact the environment, health and space for unnecessary. The activities on on-line shopping are increasing and the usages of paper boxes are worrying for the country. The population (2019) in China is approximately to 1.4 Billion with the penetration rates on online shopping reached $55.8 \%$. The estimated amount of on-line shopping in 2019 closed to USD 1.9 Trillion and the volume is increasing between 8 $-12 \%$ every year. Online shopping is motivated by product range, price advantages and availability of reviews. This study also proposes a framework to improve understanding on which psychological factors may increase the rate on returning the paper-boxes from online-shopping. The framework uses the constructs of Theory of planned behavior (TPB) as a basis, extending an exogenous factors and applies to the pro-environmental activities' context. At the end the articles show that the intention in returning the paper boxes from online shopping are not only affected by attitude, subjective norms andPerceived Behavioral Control (PBC) but also by exogenous factors.
\end{abstract}

Keywords:on-line shopping, reverse logistics, paper boxes, recycling processes, costs saving, environmental impacts and campaign

\section{Introduction}

The total population (2019) in China is approximate to 1.4 Billion with the penetration rates on online shopping reached 55.8\%. The estimated amount of on-line shopping in 2019, amounting to USD 1.9 Trillion (Statista, 2019) and the volume is increasing between $8-12 \%$ every year(Worldometer,2019). With the growth of express delivery business, the derived express packaging garbage including paper-boxes, raw papers and plastics are growing. According to Zhao \& Ma, at al. 2017, the express service industry will cost paper-box 19.2 billion units. However, the actual recovery rate of paper-boxes (cardboard) is less than 10\% (Zhang, 2018). Wu Siyu (2017) believed that the express service cartons can be recycled for two to three times. If the recovery rate of these boxes is $20 \%$, the purchase cost of one enterprise will be reduced by more than RMB 600 million between 2012 and 2016 (Gao Ying, 2018). At the same time, because these boxes are directly reused, there is almost no additional cost which will improve the profits of enterprises. Internet users, who are more than half of the country's population, mainly use the Internet for instant messaging, online search, news reading, online shopping and online payment (Zhao, 2018) which makes online shopping has become shopping mode accepted by people in the new era. Thus, actually the current recycling management of paper-boxes leads to a great waste of resources. Interpreting this results, (Jalil, Prapinit, Melan, \& Mustaffa, 2019; Loon, Hassan, \& Udin, 2016)revealed on an adoption of business intelligence, technological, individual and supply chain efficiency and involved on the final mitigation of products with appropriate manner.

In solving the problem on returning the paper-boxes at present, the reverse logistics activity should be adopted. In the past decades, many studies have been conducted in multiple aspects on general reverse logistics implement and methodology, such as forecasting on the return products (Xiong et al., 2011), factors influence adoption on reverse logistics activity (Luo Jie, 2006), barriers to reverse logistics activity (Jindal and Sangwan, 2011), cost minimization (Wang HaiPing, 2007), value return material (Fan Guicai, 2013), designing reverse logistics network for optimal collection (transportation routes) (Kui Mingming, 2009), management between two competitive closed-loop supply chains (Das \& Chowdhury, 2012). Although, the research on reverse logistics is 
getting increasing, however, most of those previous studies are concentrated on the issues arise from the company or organizational perspective. Therefore, most of the solution and result from the studies only are able to solve the issues that the companies and organizations. Prapinit, Sabar, Melan (2019) referred to the demand for logistics Studies and public knowledge especially in reverse logistics. However, in term of the discussion in the reverse logistics, literature related to individual customers is still very low and rare (Dixit \& Badgaiyan, 2016).

Besides that, the studies on cargo of reverse logistics are mainly focus on automobile and electronic wastes. Related to recycling paper-boxes from online shopping as cargo, the research only focuses on the benefits of recycling and design of systemic mechanism of recycling paper-boxes. Wu Siyu (2017) believed that the express service cartons can be recycled for two to three times. If the recovery rate of these boxes is $20 \%$, the purchase cost of one enterprise will be reduced by more than RMB 600 million between 2012 and 2016 (Gao Ying, 2018). Azizi, Hassan, Akanmu, and Melan (2019) revealed on the relationship between logistical support factors which refer to the sellers and buyers towards the mitigation of end products. At the same time, because these boxes are directly reused, there is almost no additional cost which will improve the profits of enterprises. In addition, Gao also said that if one ton of waste cartons can be recycled, the felling of 16.6 trees is reduced; $417 \mathrm{~kg}$ of air pollutants will be reduced; 588.56 kilowatt-hour electricity will be saved, 2.26 cubic meters of landfill space will be saved (Gao Ying 2018). Thus the recycling of express cartons, paper boxes are not only beneficial to the enterprises, but also to society. Tufail, Ibrahim, Melan, and Nawi, (2019) revealed on quantifying energy security in terms of economic, environmental and supply risk factors which involved on unnecessary things on costs in generating the products.

Meanwhile, Chang et al. (2017) hold that recycling systemic mechanism works of express garbage should be built up and should be guided by the state, coordinated by enterprises and participated by residents. Since the research specific on customers on recycling box is limited and rare, and it is first process of whole recycling paper-boxes process. Meanwhile express service industry costs around 19.2 billion paper boxes (Zhao \& Ma, 2018)the actual recovery rate of paper-boxes (cardboard) is less than 10\% (Zhang, 2018). Thus, the study on how to improve the rate on returning the paper-box from customer is significant. Prapinit, Sabar and Melan (2019) revealed on demand for logistics education would help the knowledge of public on the important of reverse logistics towards recycling of the products. Therefore, a framework should be developed for an in-depth understanding of consumers' intention on returning the paper boxes from online shopping. The study (Hassan, Othman, Ismail, \& Johari, 2016; Omotayo \& Melan, 2017) revealed on the factors influencing the information and communication technology (ICT) in logistics is referring with the coordination through the systems from sellers and buyers which implicate on the returning of the products through reverse logistics.

\section{Background}

\subsection{Framework on intention towards returning the paper boxes from on line shopping}

For developing an in-depth understanding of consumers' intention toward returning the paper boxes from online shopping, a framework (Figure 1) will be built up based on previous research on intention of recycling behavior. The core construct of the framework underpins the theory of planning behavior by Ajzen (1991), which is an influential research model in the behavior field. This model has been tested in recycling field in different background. The recycling process is also referred to reverse logistics in this study. Therefore, the TPB constructs can be used as a basis for this research framework.

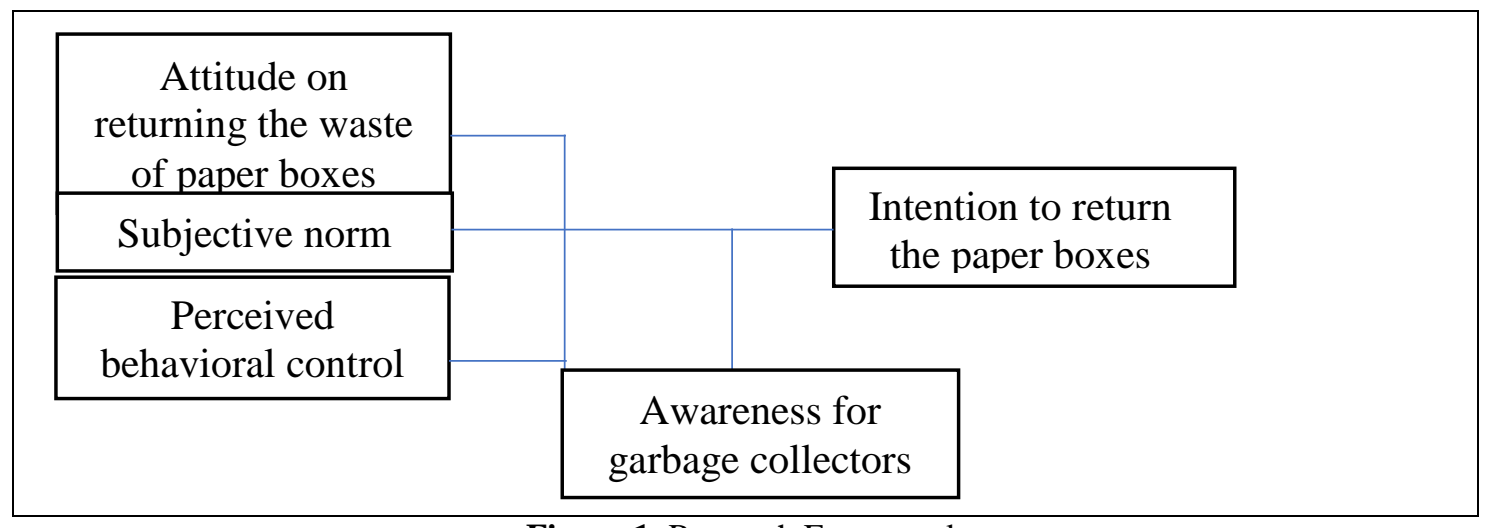

Figure 1. Research Framework

Theory of planned behavior (TPB) is extended from theory of reasoned action (TRA) (Ajzen, 1991). TRA 
holds that when the individual performs a particular behavior, the behavior will be affected by intention, and the intention will be affected by two key factors which are (1) attitude toward the behavior and (2) subjective norm. In TRA, there is the assumption that all the situation under volitional control, which brings many arguments in academic area. Since in the real situation, there is very rare situation, which is fully under volitional control. Therefore, in order to solve these issues, PBC is added into the TRA. PBC reflects the actual non-volitional situation and condition in certain level, the more accurately the individual can perceive on the actual situation, the more accurately the actual situation can reflect.

The TPB is free to apply and extend in different studies, in order to match and explain accurately to the characteristics in different studies. Thus many studies have been done by underpinning TPB in different contexts (Aini et al., 2002; Sidique, Lupi, \& Joshi, 2010; Latif \& Omar, 2012; Wan et al., 2012; Ramayah et al., 2012; Botetzagias et al., 2014; Echegaray \& Hansstein, 2017; Jalil, Mustakim, \& Prapinit, 2019). However, up to date, rare studies has focused on the intention on return the paper boxes for the university students by underpinning TPB; meanwhile Kazaure (2017) stated that awareness can be used to act as moderator in TPB relating to insurance industry, thus it is worth to extend TPB by incorporating additional factors (Awareness that operators will collect the paper boxes) to define more specific factors on more specific group of consumers' intention on recycling behavior on paper-boxes from online shopping for university students in China. By adding this exogenous variable, the viability and predictive nature of TPB may be improved, and the new model may be better to enable its application in the recycling intention specific for university students in China.

After introducing the basic of research framework in this section, the next section will discuss on each factor separately, relating to their respective influence on consumers' intention to return the paper boxes wasted from online shopping. This paper will discuss the influences of the three basic factors adapted from TPB at first and then secondly the paper will discuss the effects of the exogenous factors incorporated in the presented framework.

\section{Methodology}

\subsection{Intention on returning the paper boxes from on-line shopping}

According to Ajzen (1991), environmental behavior actually is self-interested behavior. Consequently, this behavior can rely on rational choice models, which includes of TPB. In detail, it holds that intention is influenced by (1) individual attitude towards performing a particular behavior, (2) subjective norms the individual perceives and (3) perceived behavioral control. The next three paragraphs will discuss on how these three factors will affect the intention on returning the paper boxes from online shopping.

\subsection{Attitude toward returning the paper boxes wasted}

Attitude can refer "good", "bad", "positive", "negative", "favorable" and "unfavorable" evaluation on consequences of performing the particular behavior (Chu and Chiu, 2013; Tang, Chen and Luo, 2011). Ajzen believed that an individual attitude toward behavior can be explained as a direct proportional to the sum of the salient belief toward the relevant attribute multiplied by the individual subjective evaluation of these attribute and consequences. So, the proportion of an attitude toward behavior is show in the equation below.

$$
A \alpha \sum b_{i} e_{i}
$$

In the above equation, $b_{i}$ is the salient belief to perform the behavior which lead to the consequences $\mathrm{i}$, and $e_{i}$ is an individual subjective evaluation on the attribute and the consequences $i$.

For general pro-environmental behaviors, many researches hold that Attitude has positive relationship with Intention (Aini et al., 2002; Sidique, Lupi, \& Joshi, 2010; Latif \& Omar, 2012; Wan et al., 2012; Ramayah et al., 2012; Botetzagias et al., 2014; Echegaray \& Hansstein, 2017). Thus author also hold that attitude towards returning the paper boxes wasted may positively affect Intention to return the paper boxes wasted from online shopping.

\subsection{Subjective norm}

According to Ajzen (1991), Subjective norm related to social factors and social norms, and referred to the perceived social pressure by the individual to perform or not to perform the specific behavior. An individual subjective norm can be explained as a direct proportional to the sum of the normative belief $\left(n_{i}\right)$ multiplied by 
the individual motivation $\left(m_{i}\right)$ on following those referents (Ajzen, 1991). The proportion of subjective norm is showed in the below equation.

$$
S N \alpha \sum n_{i} m_{i}
$$

In the above equation, $n_{i}$ presents the normative belief, which refers to related to likelihood or possibility (perceived by individual) that the other salient social referents or other important referents including individuals or groups such as family, friend, neighbors, etc. approve or disapprove a specific behavior, which will encourage or discourage the particular individual perform that specific behavior; Meanwhile $m_{i}$ presents an individual motivation to comply with those referents. For general pro-environmental behaviors, quite lots of studies prove that subjective norms have positive relationship with Intention (Ajzen, 1991; Conner \& Armitage, 1998; Z. Tang et al., 2011; Moons \& De Pelsmacker, 2015). Thus author also hold that subjective norms may positively affect Intention to return the paper boxes wasted from online shopping.

\subsection{Perceived Behavioral Control (PBC)}

PBC is an extended variable from TRA due to the issue of non-volitional control. In TPB, PBC reflects the actual non-volitional situation and condition in certain level, the more accurately the individual can perceive on the actual situation, the more accurately the actual situation can reflect. An individual PBC can be explained as a direct proportion on the sum of the control belief multiplied by the perceived power. The proportion of PBC is show in the below equation:

$$
\operatorname{PBC} \alpha \sum c_{i} p_{i}
$$

In the above equation, $c_{i}$, is the control belief which refers to the perceived probability on the situation which will make difficulty or ease for an individual toward performing a particular behavior. $p_{i}$ is the perceived power, which refers to the extent to which the control belief affects the behavior. For general pro-environmental behaviors, many researches hold that PBC has positive relationship with Intention (Ajzen, 1991; Christina Knussen et al., 2004; Z. Tang et al., 2011; Latif et al., 2012). Thus, authors also hold that PBC may positively affect Intention to return the paper boxes wasted from online shopping.

\subsection{Awareness that operator will collect the paper boxes (Moderator)}

Shyness can lead Chinese people to restrict doing thing they want in some level in the context of Chinese culture (Guan \& Wang, 2008). Thus, the shyness may restrict customers to return the paper boxes or will restrict them showing the idea to return the paper boxes. In that given scenario, it can be proposed here that even though the students may have a good attitude towards returning the paper boxes, lack of awareness (that operator will collect the paper boxes) will lead to a lack of formation of an intention to return the paper boxes UNDER CHINESE CULTURE, Additionally, despite that any other people may affect students to return the boxes, if they lack awareness (that operator will collect the paper boxes), they will have less willingness to return the boxes UNDER CHINESE CULTURE as discussed before. In a similar manner, despite that individual may have PBC (self-control) on whether or not to return the paper boxes, if they have a good awareness that operator will collect the paper boxes, they will have more ability (courage) to decide on whether to return the paper boxes. Thus, from the foregoing explanation, it is proposed that awareness can serve as a stimulant on the influence of attitude, subjective norms and perceived behavioral control on the intention to return the paper boxes.

\section{Results}

\subsection{Implication for Researchers}

This paper provides a framework that may help scholars understand the psychological factors which will affect intention to return the paper boxes from online shopping. Among those factors, three of them are from TPB which are attitude, subjective norms and PBC; and one exogenous factor performing as moderator is awareness that operator will collect the paper boxes. From the standpoint of TPB research, this paper extends the TPB model by one exogenous factor. Although TPB claims that attitude, subjective norms and PBC will have positive effect to the intention on pro-environmental activities, some researches have some inconsistent comments on attitude (Aini et al., 2002; Mahmud and Osman, 2010), subjective norms (Knussen et al., 2004; Rhodes et al., 2015) and PBC (Moons and De Pelsmacker, 2015).Meanwhile, the original TPB doesn't mention the moderator effect of awareness, however in the Chinese cultural context, authors believed that it may play its important role. Among those factors, in different context, they will show different effects to customers' intention for pro-environmental activities. Therefore, further research should be needed to determine which the factors in this framework have the most significant effect on behavioral intention to return to paper boxes from online 
shopping. Indeed, there should not be a general answer to this question, since those pro-environmental activities deals with different consumers that are from different cultural or economic context. However, an effort could be made to filter out the relatively less significant factors in different situations and to abstract a new conceptual framework.

\subsection{Implication for Practitioners}

The framework proposed in this article is of relevance to express agencies, education system and governments, since it enables them to assess the features that specifically attract consumers to return the paper boxes from online shopping. By collecting the high-volume paper boxes, it definitely decreases the operational cost from the express organization; meanwhile it also can decrease the social cost and solve the environmental problem.Understanding consumers' motivations to return the paper boxes is of major importance in express agencies, education system and governments making adequate strategic and marketing decisions to increase rate of returning paper boxes to express agencies from customers. For instance, this framework shows that consumers' intention toward returning paper boxes form online shopping is not only influenced by attitude, but is also significantly predicted by subjective norms. Therefore, the education system (universities) should encourage a little amount students' (high quality students) to perform this activity first. Then it will affect the normal students to perform returning paper boxes. Next to this, how do they feel the situation for returning the paper boxes also affect their intention toward returning the paper boxes, which implicates that the governments and education system (universities) should try to educate the students the positive thinking relating to the situation. Furthermore, authors believed that the lack of awareness (that) will discourage university students to return the paper boxes. Thus, in order for customers to return the paper boxes, the express agencies should set up their shops (stations) with notes like that "we appreciate your returning paper boxes".

\section{Discussion}

As like any conceptual model, this model also has its limitations. First, authors have set up a conceptual framework that includes psychological factors considered to drive customers to return paper boxes from online shopping. Although the current framework is on a combination of results from many different studies relating to the pro-environmental activities, there should always be psychological factors, which can affect consumers' intention to perform pro-environmental activities, and which are not included in the literature to date, or which is addressed in other literature studies the authors may not relate. However, authors are confident that an overview of the most relevant factors in this context has been showed up. A second limitation of current paper is that this framework is the result of a literature review and has never been tested by empirical evidence. This implies that the caution should be considered in applying the findings that derive from this framework. Finally, the number of previous researches, which were discussed in this paper, may be also limited.

\section{Conclusion}

While a large number of customers in China frequently have online shopping, it leads lots of paper boxes. Meanwhile the rate of recycling the wasted paper boxes is very row, which makes a serious organizational cost, environmental problems and social cost in China. The research on improving the rate of returning paper boxes should be conducted. The concept of reverse logistics will also be taking place. Therefore, this paper proposes a framework to increase researchers' understanding which psychological factors may increase the rate on returning the paper-boxes from online-shopping from customer perspective. The framework uses the constructs of TPB as a basis, extended by exogenous factors and applies it to the pro-environmental activities' context. This article shows that and intention to return the paper boxes wasted from online shopping are not only affected by attitude, subjective norms and PBC, but also by exogenous factors as awareness as moderator.

\section{References}

1. Ajzen, I. (1991), The theory of planned behavior. Organizational Behavior and Human Decision Processes, 50(2), 179-211. http://doi.org/10.1016/0749-5978 (91)90020-T

2. Aini, M., Fakhru'l-Razi, A., Lad, S. M., \& Hashim, A. (2002). Practices, attitudes and motives for domestic waste recycling. International Journal of Sustainable Development \& World Ecology, 9(3), 232-238.

3. Azizi, A. S., Hassan, M. G., Akanmu, M. D., \& Melan, M. (2019). Relationship between logistical support factors and effective contract management in royal Malaysian navy. International Journal of Supply Chain Management, 8(3), 1010-1017. Retrieved from www.scopus.com

4. Botetzagias, I., Dima, A., \& Malesios, C. (2014). Extending the Theory of Planned Behavior in the 
context of recycling: The role of moral norms and of demographic predictors. Resources, Conservation \& Recycling, 95(2015), 58-67. https://doi.org/10.1016/j.resconrec.2014.12.004

5. Conner, M., \& Armitage, C. J. (1998). Extending the Theory of Planned Behavior: A review and avenues for further research. Journal of Applied Social Psychology, 28(15), 1429-1464. https://doi.org/10.1111/j.1559-1816.1998.tb01685.x

6. Knussen, C., Yule, F., MacKenzie, J., \& Wells, M. (2004). An analysis of intentions to recycle household waste: The roles of past behaviour, perceived habit, and perceived lack of facilities. Journal of Environmental Psychology, 24(2), 237-246. https://doi.org/10.1016/j.jenvp.2003.12.001

7. Chang Cheng, Cheng Xing, Wu Jing \& Liu Yangcheng (2017), The Feasibility and The Strategies on How to Process Express Package Waste in Mass around The City, China Business and Market, 2017,4(12):179-189.

8. Chu, P.-Y., \& Chiu, J.-F. (2003). Factors influencing household waste recycling behavior: Test of an integrated Model. Journal of Applied Social Psychology, 33(3), 604-626. https://doi.org/10.1111/j.1559-1816.2003.tb01915.x

9. Das, K. and Chowdhury, A.H. (2012) Designing a Reverse Logistics Network for Optimal Collection, Recovery and Quality-Based Product-Mix Planning. International Journal of Production Economics, 135, 209-22. https://doi.org/

10. 10.1016/j.ijpe.2011.07.010

11. Dixit, S., \& Badgaiyan, A. J. (2016). Towards improved understanding of reverse logistics - Examining mediating role of return intention. Resources, Conservation and Recycling, 107, 115-128. https://doi.org/10.1016/j.resconrec.

12. 2015.11.021

13. Echegaray, F., \& Hansstein, F. V. (2017). Assessing the intention-behavior gap in electronic waste recycling: the case of Brazil. Journal of Cleaner Production, 142, 180-190. https://doi.org/10.1016/j.jclepro.2016.05.064

14. Fan Guicai (2013), Research on the mode of operation of telecommunication terminals material reverse logistics of JX Telecommunications Company, Master These, University NanChang.

15. Gao Ying (2018), Research on Recycling Self-run E-commerce' Parcel Carton Strategy Selection Considering Customer Behavior, Master Dissertation, Beijing

16. Hassan, M. G., Othman, A. A., Ismail, M. A., \& Johari, N. A. (2016). Supplier-manufacturer communication behavior and trust issues in outsourcing best practices. Journal of Engineering and Applied Sciences, 11(8), 1721-1726. doi:10.3923/jeasci.2016.1721.1726

17. Jalil, N. A., Prapinit, P., Melan, M., \& Mustaffa, A. B. (2019). Adoption of business intelligence technological, individual and supply chain efficiency. Paper presented at the Proceedings - 2019 International Conference on Machine Learning, Big Data and Business Intelligence, MLBDBI 2019, 67-73. doi:10.1109/MLBDBI48998.2019.00021

18. Jindal, A., \& Sangwan, K. S. (2011). Development of an interpretive structural model of barriers to reverse logistics implementation in Indian industry. In Globalized solutions for sustainability in manufacturing (pp. 448-453). Springer, Berlin, Heidelberg.

19. Kazaure, M. A., \& Hudaib, M. (2019). Extending the Theory of Planned Behavior to Explain the Role of Awareness in Accepting Islamic Health Insurance (Takaful) by Microenterprises in Northwestern Nigeria. Journal of Islamic Accounting and Business Research.

20. Kui MingMing (2009), The Study on Network Planning of Reverse Logistics, Master Dissertation, Xiamen University China.

21. Latif, S. A., \& Omar, M. S. (2012). Recycling behaviour in Tioman island: A case study. Procedia Social and Behavioral Sciences, 36(June 2011), 707-715. https://doi.org/10.1016/j.sbspro.2012.03.077

22. Loon, L. K., Hassan, M. G., \& Udin, Z. M. (2016). The effect of supply chain technology adoption: An empirical study of textile and apparel industry in Malaysia. Journal of Engineering and Applied Sciences, 11(8), 1727-1734. doi:10.3923/jeasci.2016.1727.1734

23. Luo Jie (2006), The Development of Reverse Logistics, Xian Dai Shang Ye, 2006, 10 14-15.

24. Guan RunYing \& Wang Qianqian (2008), The review of theory of shyness, Liao Ning Jiao Yu Xing Zheng Xue Yuan Xue Bao, Vol 5, 2008.

25. Moons, I., \& De Pelsmacker, P. (2015). An extended decomposed theory of planned behaviour to predict the usage intention of the electric car: A multi-group comparison. Sustainability (Switzerland), 7(5), 6212-6245. https://doi.org/10.3390/su7056212

26. Mahmud, S. N. D., \& Osman, K. (2010). The determinants of recycling intention behavior among the Malaysian school students: an application of theory of planned behaviour. Procedia - Social and Behavioral Sciences, 9, 119-124.

27. Omotayo, A. A., \& Melan, M. (2017). Factors Influencing the Information and Communication Technology (ICT) of Third Party Logistics in Malaysia. International Journal of Supply Chain 
Management, 6(2), 202-208.

28. Oberlo (2019). Online shopping statistics; https://my.oberlo.com/blog/online-shopping-statistics.

29. Prapinit,P., Sabar,R., Melan, M. (2019) Demand for Logistics Management Studies in North Eastern Thailand International Journal of Supply Chain Management, Vol 8, No 5.

30. Ramayah, T., Lee, J. W. C., \& Lim, S. (2012). Sustaining the environment through recycling: An empirical study. Journal of Environmental Management, 102, 141-147. https://doi.org/10.1016/j.jenvman.2012.02.025

31. Rhodes, R. E., Beauchamp, M. R., Conner, M., de Bruijn, G.-J., Kaushal, N., \& Latimer-Cheung, A. (2015). Prediction of depot-based specialty recycling behavior using an extended Theory of Planned Behavior. Environment and Behavior, 47(9), 1001-1023. https://doi.org/10.1177/0013916514534066

32. Statistics of Post Operation in China, Government Report, Retrieved at: http://www.spb.gov.cn/xw/dtxx_15079/201901/t20190116_1746179.html

33. Sidique, S. F., Lupi, F., \& Joshi, S. V. (2010). The effects of behavior and attitudes on drop-off recycling activities. Resources, Conservation and Recycling, 54(3), 163-170. https://doi.org/10.1016/j.resconrec.2009.07.012

34. Statista (2019) On-line shopping in China; https://www.statista.com/aboutus/our-research-commitment

35. Tang, Z., Chen, X., \& Luo, J. (2011). Determining Socio-Psychological Drivers for Rural Household Recycling Behavior in Developing Countries. Environment and Behavior, 43(6), 848-877. https://doi.org/10.1177/0013916510375681

36. Tufail, M. M. B., Ibrahim, J. A., Melan, M., \& Nawi, M. N. M. (2019). Novel approach of quantifying energy security in terms of economic, environmental and supply risk factors. Journal of Advanced Research in Fluid Mechanics and Thermal Sciences, 57(1), 100-109.

37. Wan, C., Cheung, R., \& Shen, G. Q. (2012). Recycling attitude and behaviour in university campus: a case study in Hong Kong. Facilities, 30(13/14), 630-646. https://doi.org/10.1108/02632771211270595

38. Wu Siyu (2017), The Cost and The Strategies on Express Package Recycling, Market Modernization, 2017(12):53-55.

39. XIONG, Z. K., GENG, L. J., \& NIE, J. J. (2011). An Evaluation Model and Algorithm of Reverse Logistics Provider Based on FCM Method. Journal of Industrial Engineering and Engineering Management, 1.

40. Worldmeter (2019). Total population in China, https://www.worldometers.info/world-population/chinapopulation/

41. Zhao Dong-qing (2018), The reseach of the package of cargo in post service on E-commerce, China Academic Journal Electronic Publishing House. Vol. 2018.12.005

42. Zhao Teng-fei \& Ma Tian-yuan (2018), The Appearing of Green Logistics, People's Daily Overseas Edition 03, April, 2018. Retrieved at:http://www.cssn.cn/zx/ shwx/shhnew/201804/t20180403_3896368.shtml

43. Zhang Jun (2018), Discussion on the feasibility of bamboo shared express boxes, Logistics Sci-Tech, No.8, 2018 